\title{
Sensory profile of hemicellulose-rich wood extracts in yogurt models
}

\author{
Satu Kirjoranta $\cdot$ Antti Knaapila $\cdot$ Petri Kilpeläinen $・$ Kirsi S. Mikkonen $₫$
}

Received: 27 February 2020/ Accepted: 17 June 2020/Published online: 26 June 2020

(C) The Author(s) 2020

\begin{abstract}
Wood is an abundant and sustainable source of emerging food ingredients, namely hemicelluloses that fulfil a number of requirements for functional hydrocolloids. Hemicelluloses, especially spruce galactoglucomannans (GGM) and birch glucuronoxylans (GX), have potential to be used as stabilizers in various foods such as yogurts, beverages, dressings, and desserts. However, in addition to good technological functionality, safety, and low price, the applicability and market potential of new hydrocolloids is determined by their sensory properties. The present study reports, for the first time, the sensory profile of spruce GGM and birch GX in food. Sensory
\end{abstract}

profiles from generic descriptive analysis of GGMand GX-rich extracts, processed by spray drying or ethanol precipitation, were compared in three types of model food systems: water solutions, yogurt with solutions, and yogurt with emulsions stabilized by GGM or GX. Gum Arabic was included for comparison with a commercial ingredient known to have a mild flavor. The results showed that GGM and GX have a woody flavor, which can be reduced by ethanol precipitation and, in yogurt, masked by other food ingredients.

S. Kirjoranta · A. Knaapila · K. S. Mikkonen ( $\square)$ Department of Food and Nutrition, University of Helsinki, P.O. Box 66, Agnes Sjöbergin katu 2, 00014 Helsinki, Finland e-mail: kirsi.s.mikkonen@helsinki.fi

P. Kilpeläinen

Natural Resources Institute Finland (LUKE), Tietotie 2, 02150 Espoo, Finland

\section{K. S. Mikkonen}

Helsinki Institute of Sustainability Science, Faculty of Agriculture and Forestry, University of Helsinki, Helsinki, Finland 


\section{Graphic abstract}

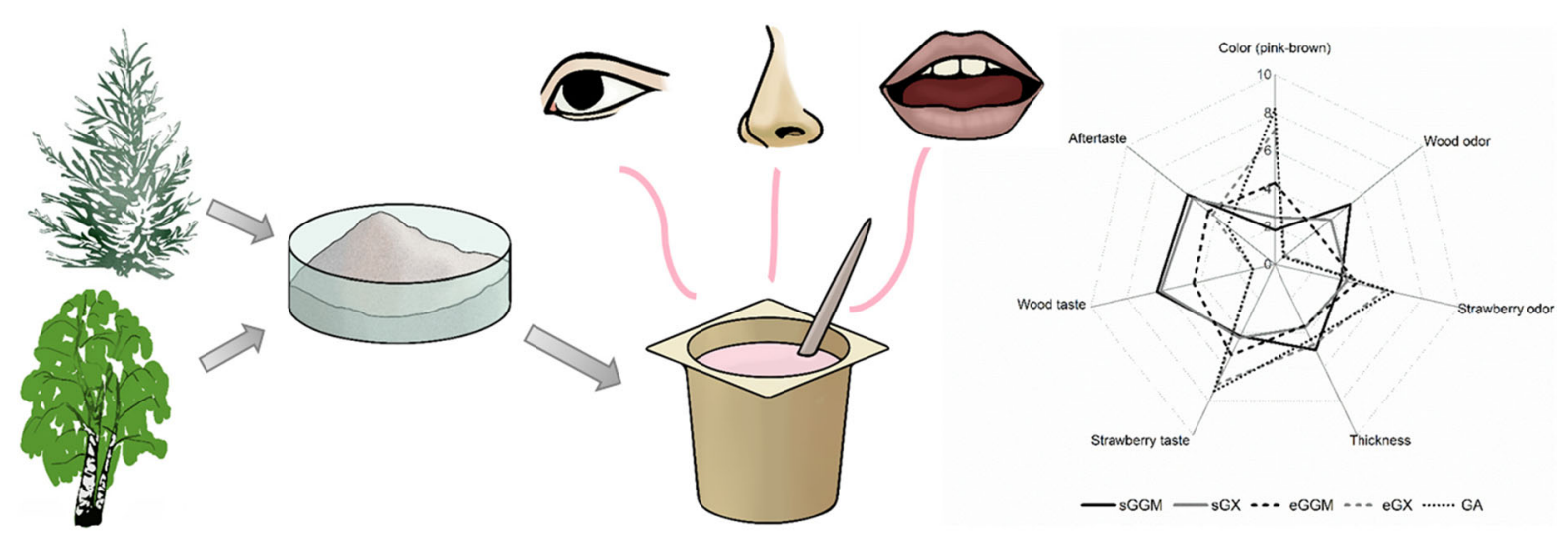

Keywords Descriptive analysis .

Galactoglucomannans · Glucuronoxylans ·

Emulsions · Sensory evaluation

$\begin{array}{ll}\text { Abbreviations } \\ \text { GX } & \text { Glucuronoxylans } \\ \text { GGM } & \text { Galactoglucomannans } \\ \text { GA } & \text { Gum Arabic } \\ \text { PHWE } & \text { Pressurized hot water extraction } \\ \text { s } & \text { Spray-dried } \\ \text { e } & \text { Ethanol-precipitated }\end{array}$

\section{Introduction}

With emerging biorefineries, industries are extensively exploring pathways to valorize lignocellulosic biomass in various alternative products (Mikkonen 2020). Hemicelluloses are abundantly available, constituting 20-35\% of wood biomass (Sjöström 1993). Technologies already exist to efficiently separate wood hemicelluloses, lignin and cellulose (Von Schoultz 2015). These processes contribute to more economic use of natural resources, and respond to the strategic aim for resource-wise circular economy (European Commission 2019). To make the industrial recovery of hemicelluloses worth investment, development of value-added applications is needed.

Hemicelluloses are non-cellulosic polysaccharides that occur in the cell walls of all terrestrial plants. Abundant industrial sources for wood hemicelluloses include thermomechanical pulping process water
(Willför et al. 2003), saw meal (Kilpeläinen et al. 2014), or pre-hydrolysate of dissolving pulp, which is often burnt at low efficiency (Saadatmand et al. 2013). Softwoods contain 20-25 wt \% hemicelluloses, mainly galactoglucomannans (GGM), while hardwoods contain 25-35 wt\%, the majority of which are glucuronoxylans (GX). In the Nordic countries, pine (Pinus sylvestris), spruce (Picea abies), and birch (Betula sp.) are the most important industrial wood species (Luke-Natural Resources Institute Finland 2019). Wood hemicelluloses are not currently isolated for industrial use, but they show great potential as novel food hydrocolloids (Mikkonen et al. 2016a, b; Valoppi et al. 2019b).

The food industries are actively seeking new natural ingredients and additives that fulfill multiple requirements (McClements et al. 2017). Successful food compounds need to be not only safe and economical, but also have desirable functional and sensory properties. Wood hemicelluloses have unique properties compared to previously known hydrocolloids. Spruce GGM and birch GX showed excellent emulsification and stabilization capacity in rapeseed oil-in-water emulsions, being more efficient stabilizers than widely used gum Arabic (GA) (Mikkonen et al. 2016a, b). GGM and GX did not form high viscosity in aqueous solutions due to their intermediate molar mass of ca. 7000-10000 g/mol (Mikkonen et al. 2016a), but they showed capacity to reduce the surface tension of water (Mikkonen et al. 2019). GGM adsorbed at the oil-water interface and stabilized it (Bhattarai et al. 2019). Furthermore, due to the presence of lignin-derived phenolic residues that act as antioxidants, GGM and GX efficiently protected 
emulsified lipids against oxidation (Lehtonen et al. 2018; Lahtinen et al. 2019). The presence of phenolic compounds is expected to affect the sensory properties of hemicelluloses, including color, odor, and taste (Valoppi et al. 2019b). However, the isolation technique and possible purification steps affect the content of phenolic compounds in hemicelluloses (Mikkonen et al. 2019; Valoppi et al. 2019a).

GGM- and GX-rich wood extracts can be recovered without harmful chemicals e.g. by pressurized hot water extraction (PHWE), where only water is used as a solvent (Kilpeläinen et al. 2014). Our recent literature review on the potential use of GGM as a novel food source concluded that safety hazards would be highly unlikely (Pitkänen et al. 2018). On the contrary, positive health effects are expected to arise from the beneficial degradation products generated by human gut microbiota (La Rosa et al. 2019). Tests with a rat model indicated that GGM controls prostate inflammation through gut metabolites and changes in the gut microbiota (Konkol et al. 2016, 2019). GGM and GX were also identified to be suitable for sheep feed (Rinne et al. 2016). However, GGM and GX do not currently have a food grade status as ingredients or additives, and thorough safety evaluation for novel foods is required (Pitkänen et al. 2018). To promote development of these sustainable hydrocolloids, including the novel food evaluation, information on the sensory attributes of GGM and GX is essential, as the sensory quality affects the consumers' acceptance of new products and can determine the potential uses and applications of a new ingredient (Tuorila 2015). Therefore, sensory profiling is an essential part in developing novel food ingredients.

Systematic sensory profiling of spruce GGM and birch GX or products therefrom has not been performed previously. Sensory profiling of foods is often done by trained sensory panelists using generic descriptive analysis (Lestringant et al. 2019). In descriptive analysis, sensory attributes important for the studied samples are first defined qualitatively, and then the intensities of the attributes are measured quantitatively (Lawless and Heymann 2010). Results of a descriptive analysis are often visualized as a spider chart (sensory profile).

The aim of the present work was to systematically define the sensory profile of spruce GGM and birch GX in water and in complex yogurt-based food products. The hypothesis was that GGM- and GX- rich wood extracts may introduce unique sensory properties and that the sensory profile of GGM and GX is influenced by the food matrix (yogurt). This study reveals the characteristics of GGM and GX as novel wood-based food hydrocolloids, and supports future product development that may utilize these sustainable ingredients.

\section{Experimental part}

\section{Materials}

GX-rich birch extract and GGM-rich spruce extract were recovered from wood saw meal by semi-pilot scale pressurized hot water extraction (PHWE) as described earlier by Kilpeläinen et al. (2014). Batches of about $100 \mathrm{~kg}$ fresh birch and spruce sawdust were extracted at $170{ }^{\circ} \mathrm{C}$ for $60 \mathrm{~min}$. A total of $21 \%$ sawdust was extracted with PHWE. Hemicellulose yield was $16 \mathrm{wt} \%$ of birch sawdust containing $87 \%$ GX, 6\% mannans, and 6\% other carbohydrates, and $18 \%$ of spruce sawdust containing $82 \%$ GGM, $16 \%$ xylans and $2 \%$ of other carbohydrates. The extracts were then concentrated by ultrafiltration (Bhattarai et al. 2019), and either spray-dried (sGX and sGGM) or ethanol-precipitated (eGX and eGGM). The content of carbohydrates, phenolic compounds, and extractives as well as molar mass of hemicelluloses is presented in Table 1 (Mikkonen et al. 2019). The amount of phenolic compounds was determined spectrophotometrically by the Folin-Ciocalteau method (Mikkonen et al. 2019). Nuclear magnetic resonance spectroscopy showed that the phenolic compounds were mainly composed of native lignin (Lahtinen et al. 2019).

Spray-dried Gum Arabic (GA) (CEROSPRAY K, C.E. Roeper $\mathrm{GmbH}$, Germany) was used as a comparison sample. The GA was mainly composed of arabinogalactan. Its carbohydrate content was 835 $\mathrm{mg} / \mathrm{g}$, molar mass was $194,000 \mathrm{~g} / \mathrm{mol}$ (Mikkonen et al. 2016b), and characterization by ultrahigh performance liquid chromatography coupled with diode array and fluorescence detectors showed that it contained a negligible content of phenolic compounds (Lehtonen et al. 2016). Low-lactose strawberry yogurt $(2.0 \%$ milk fat, Valio Ltd) was bought from a local supermarket. Rapeseed oil (Keiju, Bunge Finland Ltd, 
Table 1 Chemical composition of the hemicelluloses (Mikkonen et al. 2019)

\begin{tabular}{lllll}
\hline & $\begin{array}{l}\text { Carbohydrates } \\
\mathrm{g})\end{array}$ & Total phenolic compounds (mg/g Gallic acid equivalent) & $\begin{array}{l}\text { Extractives (mg/ } \\
\mathrm{g})\end{array}$ & Molar mass (g/mol) \\
\hline sGX & 578 & 71.1 & 10.5 & 4000 \\
eGX & 689 & 10.8 & 0.83 & 4300 \\
sGGM & 710 & 48.7 & 5.1 & 8200 \\
eGGM & 784 & 15.8 & 0.36 & 8200 \\
\hline
\end{tabular}

Raisio, Finland) was used as the lipid phase in emulsions.

\section{Preparation of samples}

Three types of samples were prepared from sGX, eGX, sGGM, eGGM, and GA for the sensory analysis: (I) aqueous solutions, (II) solutions mixed with strawberry yogurt, and (III) hemicellulose or GAstabilized rapeseed oil-in-water emulsions mixed with the strawberry yogurt (Table 2). The final hemicellulose or GA content in all samples was $0.5 \mathrm{wt} \%$.

To prepare the solutions, hemicelluloses or GA were dispersed in tap water by magnetic stirring for 2 h. To test these solutions in yogurt, $5 \mathrm{wt} \%$ of the solutions (containing $10 \mathrm{wt} \%$ of hemicellulose or GA) were added to yogurt and mixed with a spoon. Plain water (5 wt $\%$ ) was added to yogurt to obtain a reference sample with similar viscosity to that of the yogurt with hemicellulose/GA solutions, which have very low viscosity at low to medium concentration (Mikkonen et al. 2016a). To prepare oil-in-water emulsions (50 wt $\%$ rapeseed oil, $10 \mathrm{wt} \%$ hemicelluloses or GA, $40 \mathrm{wt} \%$ tap water), the oil was added on top of the hemicellulose or GA solutions. Emulsification was done by mechanical mixing using an Ultra Turrax (T-25 Basic, IKA, Germany) bench-top homogenizer at $11,000 \mathrm{rpm}$ for $5 \mathrm{~min}$. Emulsions $(5 \%)$ were added to the strawberry yogurt to achieve the same final hemicellulose or GA content as in the solutions (I) and yogurt samples with solutions (II). Rapeseed oil content of the yogurt samples with emulsions was $2.5 \%$, and total fat content was $4.4 \%$.

\section{Droplet size measurement}

The droplet size distribution of hemicellulose- and GA-stabilized emulsions was determined immediately after preparation, using static light scattering (Mastersizer 3000, Malvern Panalytical, UK).

Sensory analysis

The sensory analysis was conducted in the sensory laboratory at the University of Helsinki during JuneSeptember 2018. An ethical statement was requested from the University of Helsinki Ethical Review Board in the Humanities and Social and Behavioural Sciences, concerning the use of human evaluators to taste wood hemicelluloses that have not been regarded thus far as food ingredients or additives according to legislation. The literature survey by Pitkänen et al. (2018) and chemical analyses gave a strong indication of the safety of wood hemicelluloses in edible products. The ethical review board approved the research plan, which did not include swallowing of the hemicellulose samples.

Table 2 Hemicellulose and comparison samples used in sensory evaluations in experiments I-III

\begin{tabular}{|c|c|c|c|c|c|}
\hline & sGX & eGX & sGGM & eGGM & GA \\
\hline Experiment I & \multicolumn{5}{|c|}{ Hemicellulose-water solutions } \\
\hline Experiment II & \multicolumn{5}{|c|}{ Hemicellulose-water solutions added to strawberry yogurt } \\
\hline Experiment III & \multicolumn{5}{|c|}{ Hemicellulose-rapeseed oil in water emulsions added to strawberry yogurt } \\
\hline
\end{tabular}


Panel

A trained sensory panel $(\mathrm{n}=08-10$ panelists/experiment) was used in the study; each experiment included almost the same panelists. The panelists were employees, mostly researchers, of the Department of Food and Nutrition, University of Helsinki. All panelists had at least some previous experience in acting as a sensory panelist. The panelists signed the informed consent before joining the study.

\section{Procedure}

Sensory characterization of the samples was done using generic descriptive analysis with consensus training, described by Lawless and Heymann (2010). The generic method was modified as appropriate for the purposes of each experiment. The study consisted of three experiments: (I) evaluation of aqueous solutions, (II) evaluation of yogurts containing the solutions, and (III) evaluation of yogurts containing the emulsions. In the first experiment, the panelists had one training session $(\sim 1.5 \mathrm{~h})$ and two evaluation sessions (replicates). Only one training session was required for this experiment because the samples were relatively simple aqueous solutions without obvious variation in texture/mouthfeel. Panelists described the appearance, smell and taste of the solutions with several attributes. Opacity, brown color (Fig. 1), wood odor, overall odor intensity, astringency, bitterness, wood taste, and aftertaste intensity were the properties that all panelists agreed upon and were thus selected to be evaluated.

In both the second and third experiments, the panelists had two training sessions $(\sim 1.5 \mathrm{~h}$ each $)$ and two evaluations. In the training sessions, panelists evaluated samples visually, and by smelling and tasting. Panelists were encouraged to suggest any possible sensory attributes they found in the samples, especially when they observed differences among the samples. All of the suggested attributes were listed and discussed together. The visual, odor and taste attributes that all panel members agreed upon were selected to be used in the evaluations. In contrast to hemicellulose-water solutions, the panelists did not perceive astringency or bitterness in the yogurt samples. Based on the opinions of the panelists, pink-brown color, wood odor, strawberry odor, strawberry taste, wood taste, and wood aftertaste were selected for evaluation in the second experiment. Pink-brown color (Fig. 2), strawberry odor, wood odor, thickness in spoon, strawberry taste, wood taste, and aftertaste intensity were selected for evaluation in the third experiment, since all panelists agreed on finding them in the samples (Table 3). Reference samples were also decided in the training sessions.During the evaluation sessions, the selected attributes were evaluated using visual analog scales. Data were collected using Fizz software (version 2.51, Biosystemes, Couternon, France). Responses to the scales were converted to numerical data $(0-10$, corresponding to $0-100 \%$ distance from the left end of a scale). From the start of an evaluation session, all samples of the given experiment were available to a panelist in a sensory evaluation booth; all attributes related to a sensory modality (e.g. smell) were evaluated for a given sample before evaluating the same attributes for the following sample (on a separate screen). Only after evaluating all samples for a particular sensory modality, the panelist was allowed to proceed to evaluate attributes of the next sensory modality (without return option).

Samples were coded using 3-digit random codes and presented to the panelists in a randomized order. Tap water was provided for palate cleansing. The second evaluation was a repetition of the first one. Samples listed in Table 3 were used as references for the extreme ends (points 0 and 10).

\section{Data analysis}

The data was analyzed using IBM SPSS Statistics 25 software (Armonk, New York, USA). For each experiment, data from the two evaluation sessions (replicates) were averaged, and differences among the samples (within an experiment) were studied for each attribute using one-way analysis of variance (ANOVA) with Tukey's Post Hoc test. The criterion for statistical significance was set to alpha $=0.05$.

\section{Results}

Experiment I: hemicellulose-water solutions

The plain wood hemicellulose solutions were first analyzed to determine their sensory profile without other food components. The sGGM and sGX solutions 


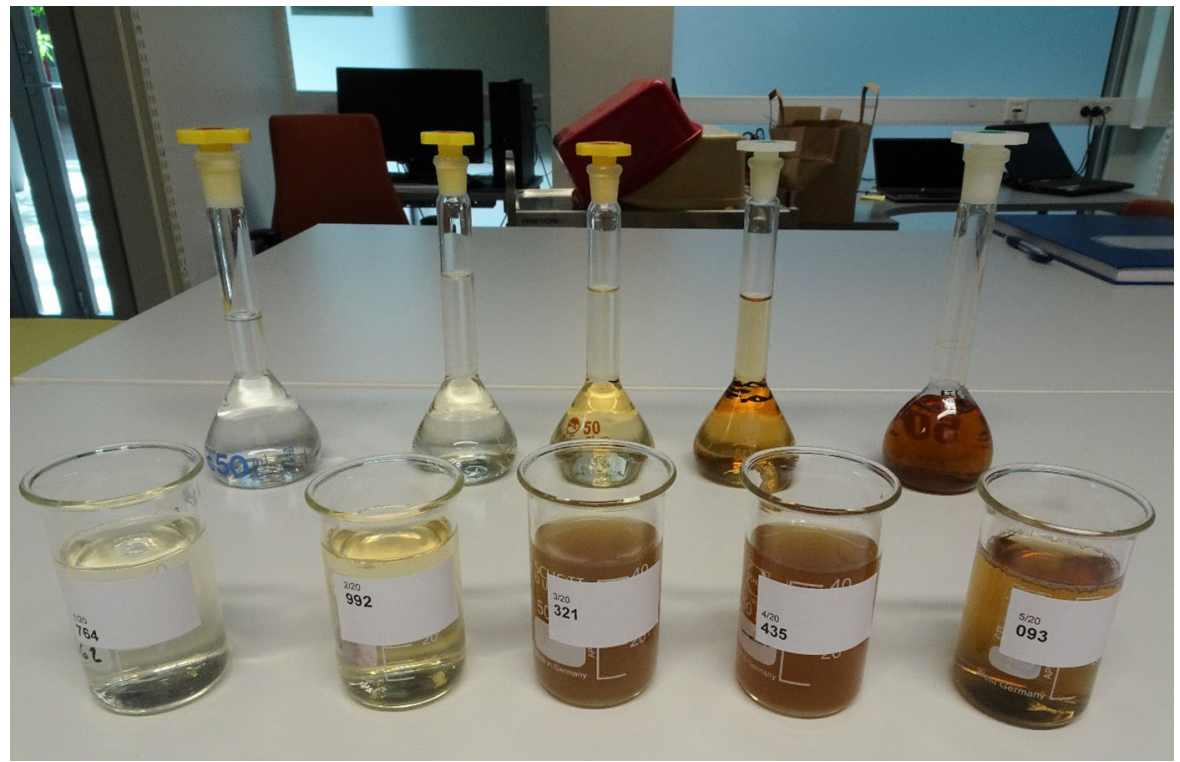

Fig. 1 Evaluation of the intensity of the brown color (experiment I). Samples in the front, reference samples behind. Samples from left to right: $0.5 \mathrm{wt} \%$ GA, eGX, sGGM, sGX, and
eGGM in water. Reference samples from left to right: water, burned sugar $0.0004 \%, 0.002 \%, 0.01 \%$ and $0.02 \%$

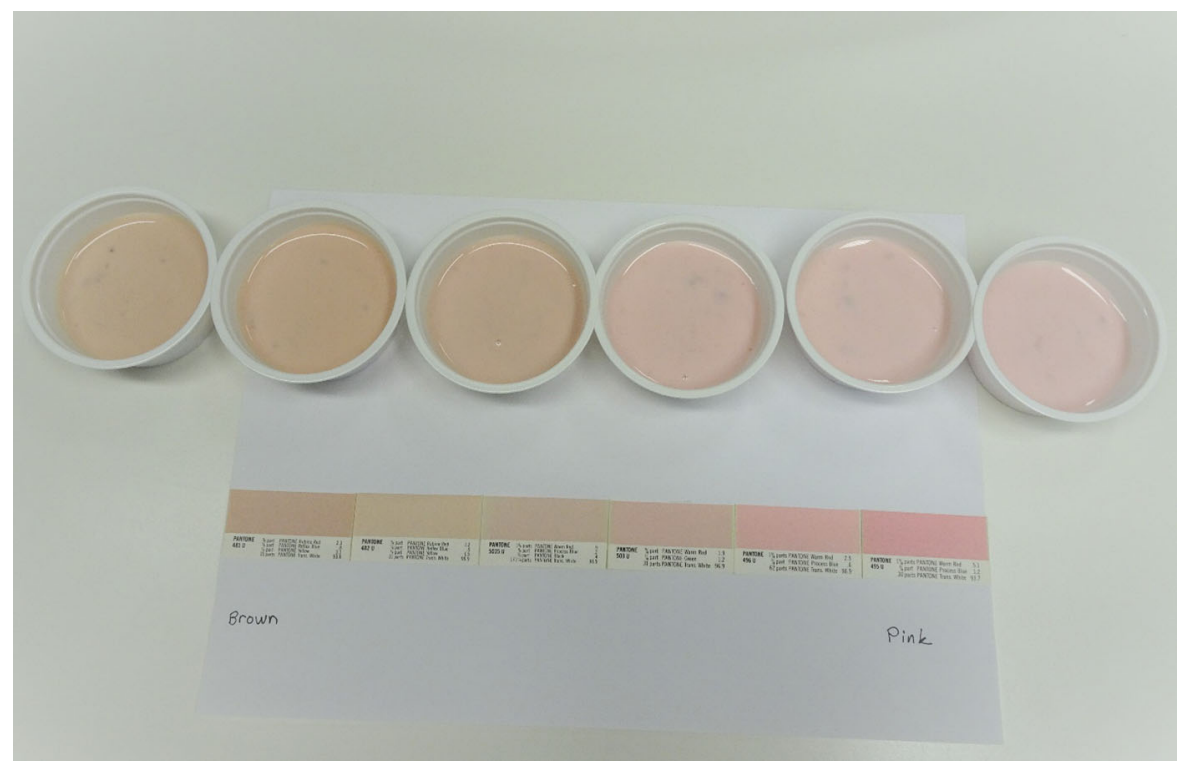

Fig. 2 Evaluation of the pink-brown color using the Pantone standard color map. Samples from left to right: yoghurts with sGGM, sGX, eGGM, eGX, GA, and water. Scale from left to right: 481U, 482U, 5035U, 503U, 496U and 495U

were opaque and brown, and they had a strong wood odor and taste. They were also astringent and bitter, sGX more so than sGGM. The eGGM solution was brown in color, but did not have a remarkable woodlike odor or taste. The eGX solution showed very low bitterness and astringency, and it did not have wood odor or taste (Fig. 3). Differences between spray-dried (sGX and sGGM) and ethanol-precipitated (eGX and eGGM) hemicelluloses were more notable than differences between the wood species (spruce GGM or birch GX). The statistically significant differences 
Table 3 Evaluated sensory attributes, labels of scale end points, and corresponding reference samples used

\begin{tabular}{|c|c|c|c|c|c|}
\hline Attribute & Experiment & Reference at 0 & Label at 0 & Reference at 10 & Label at 10 \\
\hline \multicolumn{6}{|l|}{ Appearance } \\
\hline Opacity & I & Water & Transparent & Cloudy apple juice & Very opaque \\
\hline Intensity of brown color & I & Water & Not at all & $\begin{array}{l}\text { Burned sugar solution } \\
0.02 \%\end{array}$ & Intense brown \\
\hline Pink-brown color & II, III & $\begin{array}{l}\text { Pantone color } \\
\quad 481 \mathrm{U}\end{array}$ & Brownish & Pantone color $495 \mathrm{U}$ & Pinkish \\
\hline \multicolumn{6}{|l|}{ Odor } \\
\hline Wood odor & I, II, III & Water & Not at all & Wood chips & Strong wood odor \\
\hline Overall odor intensity & I & No reference & Not at all & No reference & Very strong \\
\hline Strawberry odor & II, III & Water & Not at all & $\begin{array}{l}\text { Strawberry juice } \\
\text { Marli Juissi }\end{array}$ & Very strong \\
\hline \multicolumn{6}{|l|}{ Texture } \\
\hline Thickness in spoon & III & Water & Not at all & Turkish yogurt & Very thick \\
\hline \multicolumn{6}{|l|}{ Flavor } \\
\hline Bitterness & I & Water & Not at all & Caffeine taste pad & Very strong \\
\hline Astringency & I & Water & Not at all & $\begin{array}{l}\text { Tannic acid solution } \\
0.1 \%\end{array}$ & Very astringent \\
\hline Wood taste & I, II, III & Water & Not at all & Wooden stirrer stick & Very strong \\
\hline Strawberry taste & II,III & Water & Not at all & $\begin{array}{l}\text { Strawberry juice } \\
\text { Marli Juissi }\end{array}$ & Very strong \\
\hline \multicolumn{6}{|l|}{ Aftertaste } \\
\hline Aftertaste intensity & I, III & No reference & Not at all & $\begin{array}{l}\text { Very strong (no } \\
\text { reference) }\end{array}$ & \\
\hline $\begin{array}{l}\text { Wood aftertaste (after spitting out } \\
\text { the sample) }\end{array}$ & II & No reference & Not at all & Wooden stirrer stick & $\begin{array}{l}\text { Very strong wood } \\
\text { aftertaste }\end{array}$ \\
\hline
\end{tabular}

between samples from the Tukey's test are shown in Table 4.

Experiment II: yogurts with hemicellulose solutions

Yogurt was used as a model food product to characterize the sensory profile of hemicelluloses in a complex matrix with other components such as proteins, lipids, and flavor compounds. The studied samples formed two groups based on their sensory profile; the sGX and sGGM formed one group, and the other samples formed another group with a similar profile. Wood taste and aftertaste was found in yogurts containing sGX and sGGM, which also showed a brownish color. The yogurt samples with eGX, eGGM, and GA did not show remarkable wood odor or wood taste, and their color was pinker than that of the sGX and sGGM samples. Strawberry odor and taste were less intense in the yogurts with sGGM and sGX compared to the other samples, and may have been masked by the woody flavor (Fig. 4; Table 5).

Experiment III: yogurts with hemicellulose emulsions

\section{Droplet size distribution}

The droplet size distribution and average droplet size of emulsions added to yogurt were determined to confirm the distribution of oil in the matrix as fine droplets. All emulsions showed a unimodal droplet size distribution (Fig. 5). All GGM- and GX-stabilized emulsions showed a small D[3,2] average droplet size of 3-4 $\mu \mathrm{m}$ (Table 6). The GA-stabilized emulsion differed from the wood hemicellulose emulsions, as it had a much higher D[3,2] average droplet size of 12.4 $\mu \mathrm{m}$. The difference between wood hemicellulose- and 


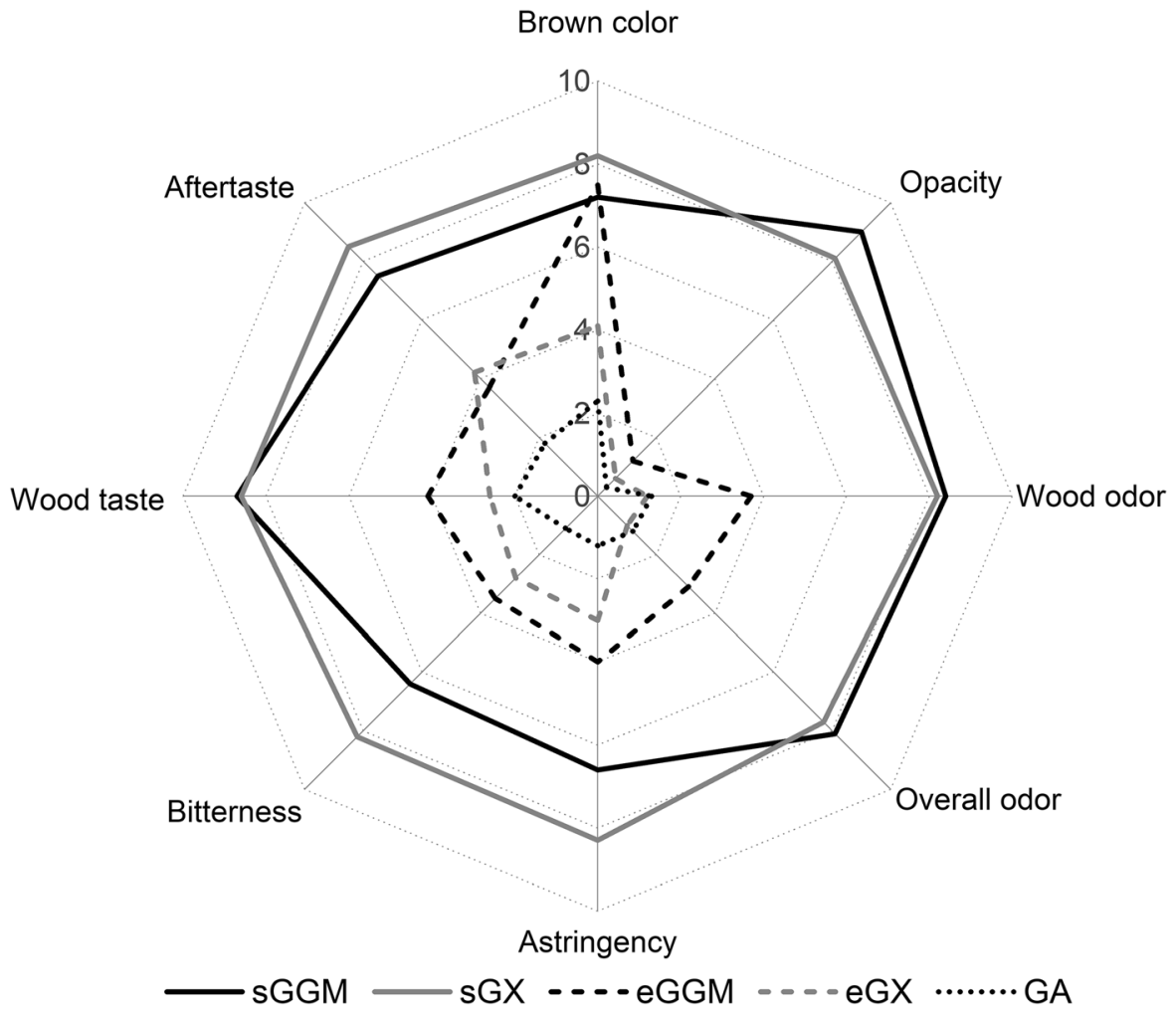

Fig. 3 Sensory profile of wood hemicellulose and GA solutions (Experiment I)

Table 4 Mean and standard deviation values of the sensory attributes of the evaluated solutions

\begin{tabular}{llllll}
\hline Attribute $^{\dagger}$ & sGGM & sGX & eGGM & eGX & GA \\
\hline Opacity & $9.0 \pm 2.0 \mathrm{~b}$ & $8.1 \pm 1.9 \mathrm{~b}$ & $1.2 \pm 1.3 \mathrm{a}$ & $0.6 \pm 0.9 \mathrm{a}$ & $0.3 \pm 0.4 \mathrm{a}$ \\
Brown color & $7.2 \pm 1.0 \mathrm{c}$ & $8.2 \pm 1.1 \mathrm{~d}$ & $7.5 \pm 1.4 \mathrm{c}$ & $4.1 \pm 0.8 \mathrm{~b}$ & $2.3 \pm 0.9 \mathrm{a}$ \\
Wood odor & $8.4 \pm 1.7 \mathrm{c}$ & $8.2 \pm 1.5 \mathrm{c}$ & $3.7 \pm 2.5 \mathrm{~b}$ & $1.2 \pm 1.4 \mathrm{a}$ & $1.3 \pm 2.0 \mathrm{a}$ \\
Overall odor intensity & $8.1 \pm 1.5 \mathrm{c}$ & $7.7 \pm 1.5 \mathrm{c}$ & $3.1 \pm 1.6 \mathrm{~b}$ & $1.0 \pm 0.6 \mathrm{a}$ & $1.2 \pm 1.5 \mathrm{a}$ \\
Astringency & $6.6 \pm 1.7 \mathrm{c}$ & $8.3 \pm 1.2 \mathrm{~d}$ & $4.0 \pm 2.4 \mathrm{~b}$ & $3.0 \pm 2.2 \mathrm{~b}$ & $1.2 \pm 0.9 \mathrm{a}$ \\
Bitterness & $6.4 \pm 1.7 \mathrm{c}$ & $8.2 \pm 1.5 \mathrm{~d}$ & $3.5 \pm 2.6 \mathrm{~b}$ & $2.8 \pm 3.0 \mathrm{a}, \mathrm{b}$ & $1.1 \pm 1.2 \mathrm{a}$ \\
Wood taste & $8.7 \pm 1.4 \mathrm{c}$ & $8.6 \pm 1.5 \mathrm{c}$ & $4.1 \pm 2.3 \mathrm{~b}$ & $2.6 \pm 2.4 \mathrm{a}, \mathrm{b}$ & $2.0 \pm 2.6 \mathrm{a}$ \\
Aftertaste intensity & $7.5 \pm 1.9 \mathrm{c}$ & $8.5 \pm 1.3 \mathrm{c}$ & $3.7 \pm 2.2 \mathrm{a}, \mathrm{b}$ & $4.2 \pm 3.4 \mathrm{~b}$ & $1.8 \pm 1.7 \mathrm{a}$
\end{tabular}

${ }^{\dagger}$ Means of a specific attribute that differ significantly between samples (within a row) are marked with different letters (a-d), with the lowest value marked with a (Tukey's test, $p<0.05$ )

GA-stabilized emulsions was clear also in the $\mathrm{D}[4,3]$ and D90 droplet size values (Table 6).

\section{Sensory analysis}

As the third food model, we used yogurt with added rapeseed oil-in-water emulsions, comprising polyunsaturated lipids to improve the lipid profile, making it comparable to traditional dairy products. Again, the main differences between samples depended on the processing method of hemicelluloses, namely spray drying or ethanol precipitation. The yogurts with emulsions stabilized with sGGM and sGX showed wood-like odor and taste, and their 


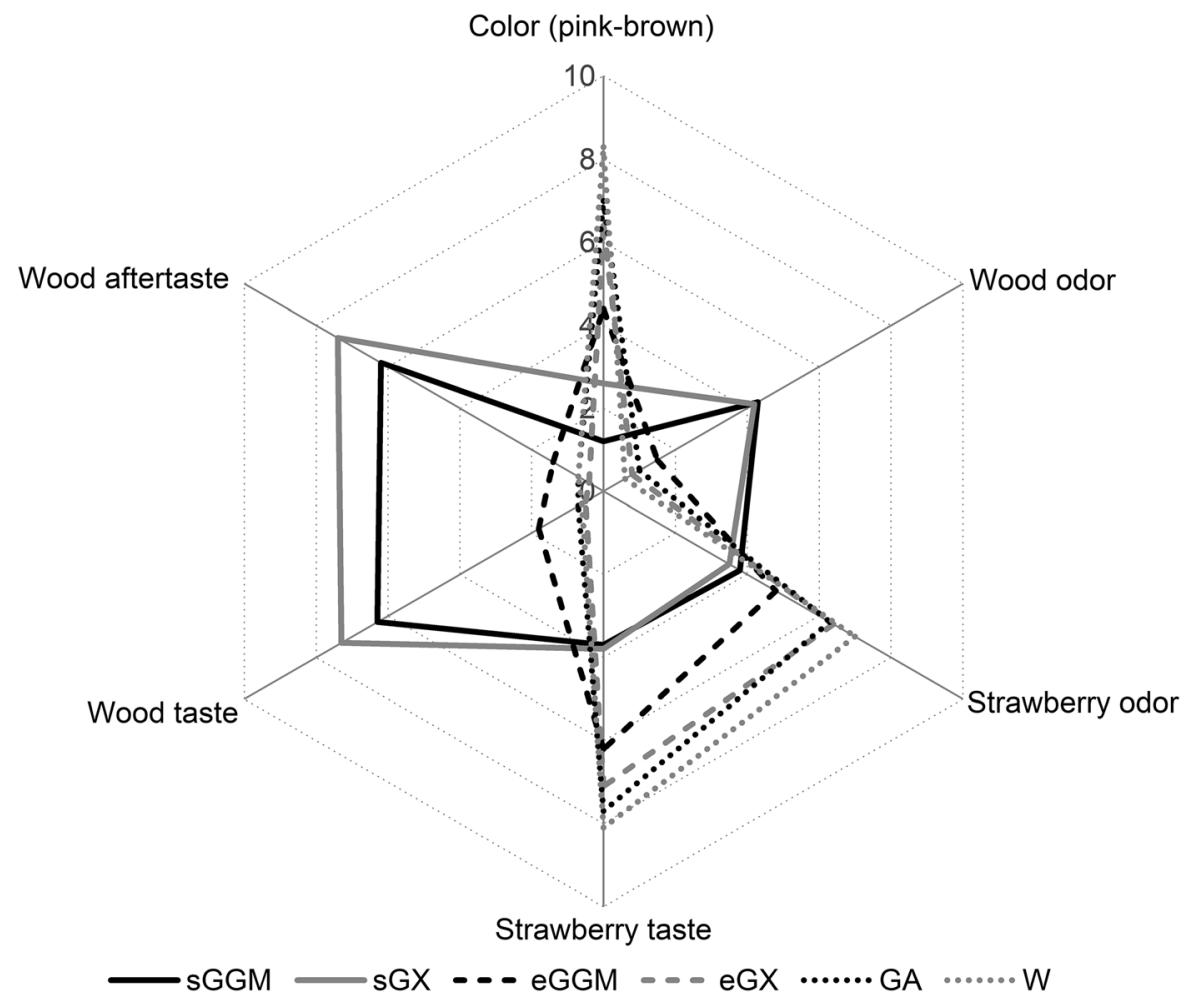

Fig. 4 Sensory profile of the yogurts with wood hemicellulose and GA solutions (Experiment II). W is control sample with added water. (Color: $0=$ brownish, $10=$ pinkish)

Table 5 Mean and standard deviation values of the attributes of the evaluated yogurt samples. W indicates the reference yogurt sample with added water. (Pink-brown: $10=$ pinkish, $0=$ brownish)

\begin{tabular}{lllllll}
\hline Attribute $^{\dagger}$ & sGGM & sGX & eGGM & eGX & GA & W \\
\hline Pink-brown & $1.2 \pm 1.0 \mathrm{a}$ & $2.6 \pm 1.0 \mathrm{~b}$ & $4.4 \pm 0.9 \mathrm{c}$ & $6.4 \pm 0.6 \mathrm{~d}$ & $7.0 \pm 0.7 \mathrm{~d}$ & $8.3 \pm 0.9 \mathrm{e}$ \\
Wood odor & $4.3 \pm 2.8 \mathrm{~b}$ & $4.2 \pm 2.5 \mathrm{~b}$ & $1.5 \pm 1.7 \mathrm{a}$ & $0.8 \pm 1.0 \mathrm{a}$ & $1.0 \pm 1.6 \mathrm{a}$ & $0.6 \pm 1.0 \mathrm{a}$ \\
Strawberry odor & $3.8 \pm 3.0 \mathrm{a}$ & $3.5 \pm 2.6 \mathrm{a}$ & $4.8 \pm 2.2 \mathrm{a}, \mathrm{b}$ & $6.4 \pm 2.1 \mathrm{~b}$ & $6.3 \pm 2.2 \mathrm{~b}$ & $7.0 \pm 2.3 \mathrm{~b}$ \\
Strawberry taste & $3.7 \pm 2.2 \mathrm{a}$ & $3.8 \pm 2.3 \mathrm{a}$ & $6.2 \pm 2.0 \mathrm{~b}$ & $7.1 \pm 1.6 \mathrm{~b}, \mathrm{c}$ & $7.7 \pm 1.7 \mathrm{~b}, \mathrm{c}$ & $8.1 \pm 1.4 \mathrm{c}$ \\
Wood taste & $6.3 \pm 2.3 \mathrm{~b}$ & $7.3 \pm 2.4 \mathrm{~b}$ & $1.8 \pm 1.8 \mathrm{a}$ & $0.5 \pm 0.6 \mathrm{a}$ & $0.7 \pm 0.9 \mathrm{a}$ & $0.6 \pm 1.0 \mathrm{a}$ \\
Wood aftertaste & $6.2 \pm 2.6 \mathrm{~b}$ & $7.4 \pm 2.3 \mathrm{~b}$ & $1.4 \pm 1.4 \mathrm{a}$ & $0.4 \pm 0.7 \mathrm{a}$ & $0.7 \pm 1.0 \mathrm{a}$ & $0.7 \pm 1.4 \mathrm{a}$ \\
\hline
\end{tabular}

${ }^{\dagger}$ Means of a specific attribute that differ significantly between samples (within a row) are marked with different letters (a-d), with the lowest value marked with a (Tukey's test, $p<0.05$ )

aftertaste was rather intense. Ethanol precipitation greatly decreased the woody flavor. Notably, the yogurt with eGX-stabilized emulsion had a similar sensory profile to the sample with GA - there was no significant wood odor or taste, and the yogurt's original strawberry odor and taste remained as intense. Furthermore, thickness of the yogurts was evaluated, but there was no difference between the samples
(Fig. 6; Table 7). The thickness evaluation was supported by viscosity analysis using rheology (data not shown), which also confirmed that the added hemicelluloses did not affect the viscosity of the yogurt. 


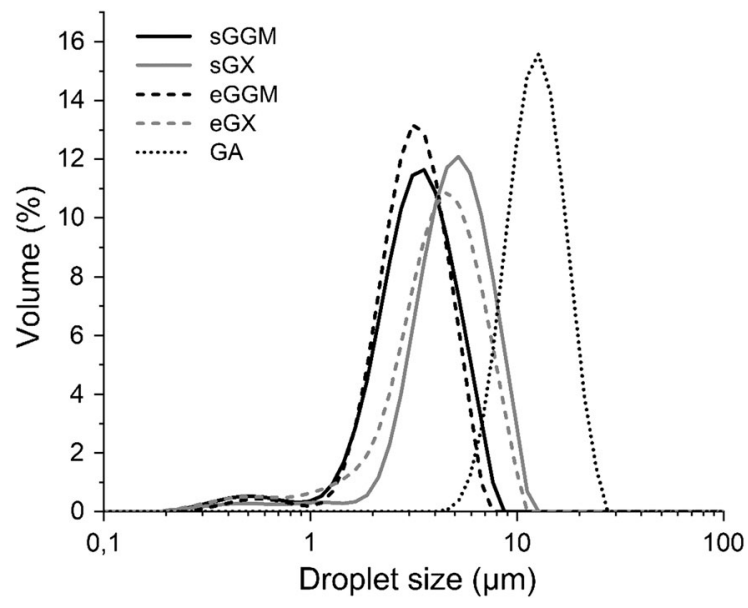

Fig. 5 Sensory profile of the yogurts containing wood hemicellulose emulsions (Experiment III). (Color: $0=$ brownish, $10=$ pinkish)

\section{Discussion}

Sensory profile of wood hemicellulose-rich water solutions

The sensory profile of wood hemicelluloses was evaluated for the first time to help define their applicability as food ingredients or additives. Wood hemicellulose-rich water solutions had typically brownish color and wood-like odor and taste, which are likely caused by phenolic compounds that are coextracted with hemicelluloses. The spray-dried wood extracts (sGGM and sGX) were rated as more opaque and brown, more intense in wood odor and overall odor, more astringent and bitter, and more intense in wood taste and overall aftertaste than the corresponding ethanol precipitated wood extracts (eGGM and eGX). This implies that these sensory characteristics are strongly contributed by components that were lost in the ethanol precipitation but remained after spray drying of the wood extracts. The composition of sGGM, sGX, eGGM and eGX was previously compared (Mikkonen et al. 2019). The sGGM and sGX showed clearly higher contents of lignin-derived phenolic compounds, as well as lignans and other extractives, than the eGGM and eGX (Mikkonen et al. 2019). In general, phenolic compounds are known for their bitter taste and astringency (Drewnowski 2001; Soares et al. 2018). The opaque appearance of the water solutions can be explained by incomplete solubility of hemicelluloses in an aqueous system. A recent study by Bhattarai et al. (2020) showed that eGGM and sGGM contain two and three size classes of colloidal particles, respectively.

Processing method (ethanol precipitation vs. spray drying) had a stronger influence on the sensory profiles of the water solutions than the origin of the hemicelluloses (spruce vs. birch wood). Spruce-derived sGGM had a rather similar sensory profile as birchderived sGX, although sGX was evaluated as slightly more bitter and astringent than sGGM. Likewise, spruce-derived eGGM had a similar sensory profile as birch-derived eGX. However, eGGM was rated as more intense in brown color, overall odor, and wood odor than eGX. Among the hemicellulose samples, the sensory profile of eGX had the least woody notes, and closely resembled that of the commercial GA.

Table 6 Mean and standard deviation values of the attributes of the evaluated emulsion-yogurt samples. $($ Color: $10=$ pinkish, $0=$ brownish)

\begin{tabular}{llllll}
\hline Attribute $^{\dagger}$ & sGGM & sGX & eGGM & eGX & GA \\
\hline Pink-brown & $1.8 \pm 0.8 \mathrm{a}$ & $2.5 \pm 0.7 \mathrm{a}$ & $4.3 \pm 0.7 \mathrm{~b}$ & $7.1 \pm 0.9 \mathrm{c}$ & $8.2 \pm 1.1 \mathrm{~d}$ \\
Wood odor & $5.1 \pm 3.1 \mathrm{c}$ & $3.8 \pm 2.7 \mathrm{~b}, \mathrm{c}$ & $2.8 \pm 2.4 \mathrm{a}, \mathrm{b}$ & $0.7 \pm 0.9 \mathrm{a}$ & $0.6 \pm 1.0 \mathrm{a}$ \\
Strawberry odor & $3.6 \pm 2.1 \mathrm{a}$ & $3.9 \pm 2.1 \mathrm{a}, \mathrm{b}$ & $4.4 \pm 2.3 \mathrm{a}, \mathrm{b}, \mathrm{c}$ & $6.0 \pm 2.1 \mathrm{~b}, \mathrm{c}$ & $6.4 \pm 2.3 \mathrm{c}$ \\
Thickness & $5.0 \pm 1.9 \mathrm{a}$ & $3.7 \pm 1.4 \mathrm{a}$ & $3.6 \pm 1.5 \mathrm{a}$ & $4.7 \pm 2.1 \mathrm{a}$ & $4.4 \pm 2.0 \mathrm{a}$ \\
Strawberry taste & $4.2 \pm 1.6 \mathrm{a}$ & $4.3 \pm 1.7 \mathrm{a}$ & $5.3 \pm 2.0 \mathrm{a}, \mathrm{b}$ & $7.0 \pm 2.0 \mathrm{~b}, \mathrm{c}$ & $7.4 \pm 1.9 \mathrm{c}$ \\
Wood taste & $6.4 \pm 2.9 \mathrm{~b}$ & $6.2 \pm 2.8 \mathrm{~b}$ & $4.4 \pm 3.1 \mathrm{~b}$ & $1.2 \pm 1.3 \mathrm{a}$ & $1.2 \pm 1.6 \mathrm{a}$ \\
Aftertaste intensity & $5.9 \pm 2.1 \mathrm{~b}$ & $5.6 \pm 2.2 \mathrm{~b}$ & $4.5 \pm 2.5 \mathrm{a}, \mathrm{b}$ & $4.2 \pm 2.7 \mathrm{a}, \mathrm{b}$ & $3.2 \pm 2.2 \mathrm{a}$ \\
\hline
\end{tabular}

${ }^{\dagger}$ Means of a specific attribute that differ significantly between samples (within a row) are marked with different letters (a-d), with the lowest value marked with a (Tukey's test, $p<0.05$ ) 


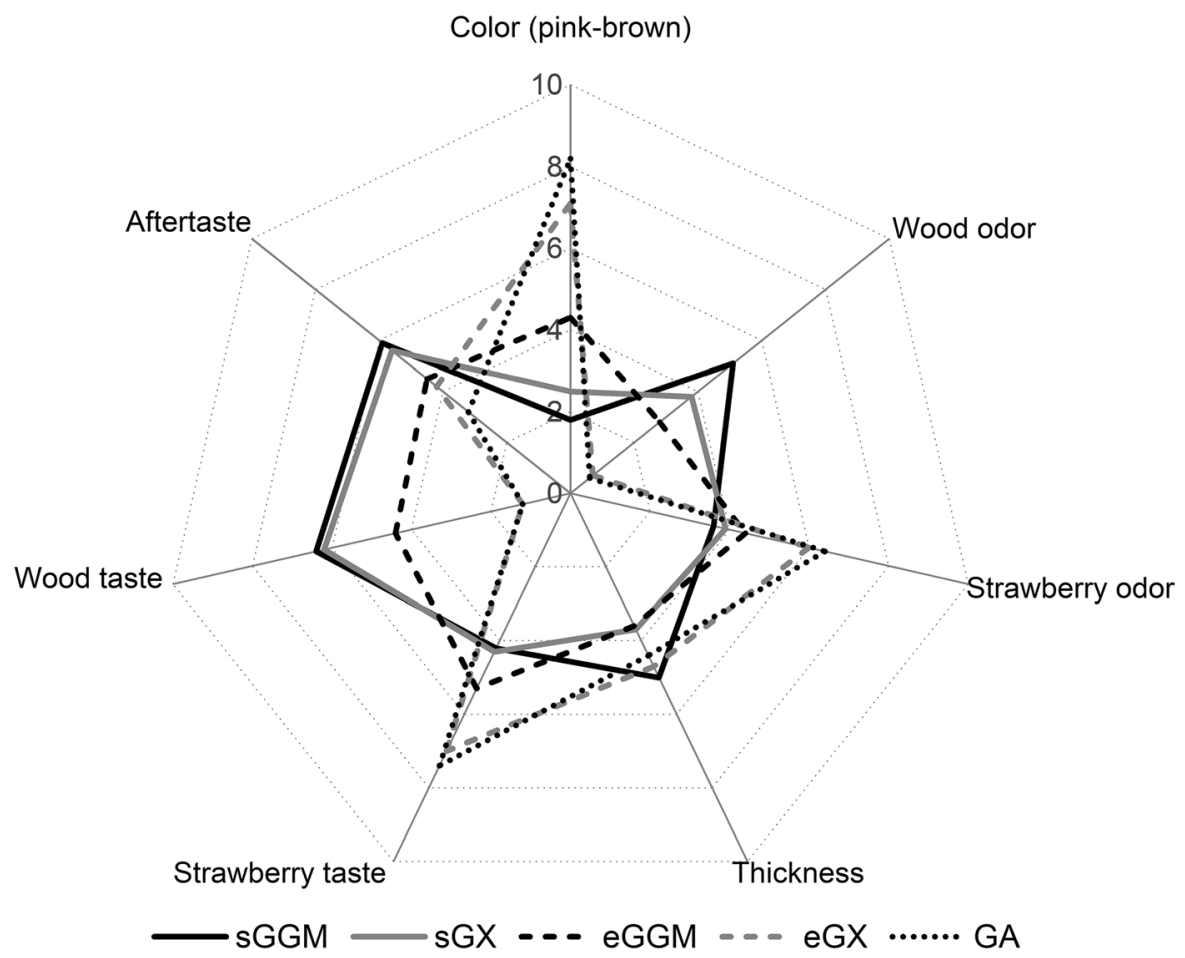

Fig. 6 Droplet size $(\mu \mathrm{m})$ distribution of emulsions

Table 7 Average droplet sizes $(\mu \mathrm{m})$ of the emulsions

\begin{tabular}{llll}
\hline Sample & D [3.2] & D [4.3] & Dx (90) \\
\hline sGGM & $2.7 \pm 0.02$ & $3.7 \pm 0.00$ & $5.8 \pm 0.01$ \\
eGGM & $2.8 \pm 0.06$ & $3.5 \pm 0.02$ & $5.3 \pm 0.02$ \\
sGX & $3.9 \pm 0.02$ & $5.5 \pm 0.01$ & $8.6 \pm 0.02$ \\
eGX & $3.0 \pm 0.01$ & $4.7 \pm 0.01$ & $7.8 \pm 0.02$ \\
GA & $12.4 \pm 0.06$ & $13.7 \pm 0.00$ & $19.6 \pm 0.06$ \\
\hline
\end{tabular}

Model product prototypes

Sensory profiles of strawberry yogurt with hemicellulose solutions followed a similar pattern to the sensory profiles of the solutions themselves. However, the yogurt characteristics partially masked the woody properties of the hemicelluloses, compared to the water solutions. Since the panel did not consider bitterness and astringency as important sensory attributes for the evaluation of the yogurt models, these attributes were not included in the sensory profiling of the yogurts. The yogurt matrix may have reduced the bitterness and astringency that were notable in the sGGM and sGX water solutions.

Again, the processing method had a stronger effect on the sensory properties than the origin of the hemicelluloses. Yogurts with spray-dried hemicelluloses (sGGM and sGX) had similar sensory profiles, which both showed much stronger woody characteristics (brown color and wood odor, taste, and aftertaste) than either of the samples with ethanolprecipitated hemicelluloses (eGGM and eGX). In contrast, the strawberry characteristics of the yogurt base (pink color and strawberry odor and taste) were perceived as more intense in eGGM and eGX than in sGGM and sGX. Thus, the woody characteristics of sGGM and sGX may have partially masked the strawberry characteristics of the yogurt.

When hemicelluloses were added to the yogurt model as an emulsion, the pattern of sensory profiles was mainly similar to those of yogurts with hemicelluloses added as a solution. Again, sGGM and sGX had obvious woody characteristics, while eGX largely retained the strawberry notes of the yogurt. However, in the yogurt with added emulsions, the sensory profile of eGGM was in between those of sGGM/sGX and 
eGX. Compared to yogurts with hemicellulose solutions, the yogurts with hemicellulose emulsions had higher fat content due to the rapeseed oil. Hemicelluloses may be located partially at the oil-droplet interface and partially in the continuous phase of emulsions (Bhattarai et al. 2019), which was miscible with the yogurt matrix.

Results for all three model systems consistently showed that the sensory profile of eGX was the most similar to that of GA, which was used as a commercial comparison sample with a very mild flavor. In yogurt models, no difference was observed in the sensory properties between eGX and GA, except in color. This suggests that eGX is a potential ingredient or additive in applications where woody sensory characteristics are not desired.

There was no correlation between the physical and sensory properties of the studied samples. The amount of emulsion added was so small that it did not cause perceivable sensory differences in texture of the yogurt samples. This finding corresponds to our earlier work, where we found that solutions and emulsions with GGM and GX showed rather low viscosity even at intermediate concentrations (Mikkonen et al. 2016a). However, panelists evaluated the sGGM sample as the thickest, albeit nominally. The droplet size distributions and average oil droplet sizes were similar in all GGM and GX emulsions. Even though the GA-stabilized emulsions had a larger average droplet size, the panelists did not find differences either in oiliness or smoothness while analyzing the samples qualitatively during the first training session.

Outlook on wood hemicelluloses as novel hydrocolloids

Since hemicelluloses occur in all terrestrial plant cell walls, they are part of many common foods such as cereal grains. Various plant-based side streams are an increasingly interesting source of natural hydrocolloids (Ralla et al. 2018). Isolated wood hemicelluloses are not traditional food ingredients or additives; however, similar compounds from other sources such as guar gum and konjac glucomannan are abundantly used, and xylans from grains are part of our common diet. On the other hand, wood-derived vanillin aroma, glycerol esters of wood rosins (E445), xylitol (E967) and steryls/stanols are being used as food ingredients or additives (Pitkänen et al. 2018). The PHWE extraction of wood saw meal yields samples rich in hemicelluloses that also contain varying amounts of co-components, mainly lignin-derived phenolic compounds (Kilpeläinen et al. 2014; Mikkonen et al. 2019). The phenolic compounds are beneficial for the functionality of hemicelluloses as emulsion stabilizers (Lehtonen et al. 2018; Mikkonen et al. 2019), but they also contribute to the sensory profile of hemicelluloserich extracts. Wood-like flavor present in sGGM and sGX (due to the phenolic co-components) could be exploited in product design for creating new flavors. If such unique flavor is not desired, it can be largely removed by ethanol precipitation, especially from GX, and masked by the other food constituents. Wood hemicelluloses are potential stabilizers, for example in yogurts, beverages, dressings, and desserts (Valoppi et al. 2019b).

Suggested future studies include determining the interaction effects of the wood-like flavors of hemicelluloses with other various ingredients. In addition, hedonic tests need to be performed to determine if products with wood hemicelluloses are acceptable for consumers.

\section{Conclusions}

Sensory profiles of wood GGM and GX were characterized as water solutions and in yogurt models. The characteristic wood-like flavor, bitter taste, and astringency were pronounced in spray-dried sGGM and sGX solutions, which was attributed to the presence of lignin-derived phenolic compounds. Ethanol precipitation, which removed a large part of phenolic compounds from the hemicellulose-rich extracts, reduced the woody flavor. Thus, the hemicellulose processing method (spray drying vs. ethanol precipitation) had a more significant effect on the sensory profile than the wood source (spruce or birch). The results support the hypothesis that lignocellulosic cocomponents in wood extracts introduce sensory attributes, which the plain polysaccharides are lacking. Furthermore, the bitterness and astringency were fully masked when wood hemicellulose solutions or emulsions were mixed with strawberry yogurt. In particular, the ethanol-precipitated eGX showed a similar sensory profile as GA, which was used as a commercial comparison sample with a mild flavor. Wood hemicelluloses showed promising sensory 
properties as sustainable novel food ingredients or additives. The intensity of woody characteristics of hemicelluloses can be adjusted to meet the needs of various food applications.

Acknowledgments Open access funding provided by University of Helsinki including Helsinki University Central Hospital. We thank the panelists for their invaluable contribution to the work, Jutta Varis for helping to organize the sensory evaluations, and Julia Varis for drawing the graphical abstract. Academy of Finland is gratefully acknowledged for funding through the Key Project programme (Project Number 305517).

Open Access This article is licensed under a Creative Commons Attribution 4.0 International License, which permits use, sharing, adaptation, distribution and reproduction in any medium or format, as long as you give appropriate credit to the original author(s) and the source, provide a link to the Creative Commons licence, and indicate if changes were made. The images or other third party material in this article are included in the article's Creative Commons licence, unless indicated otherwise in a credit line to the material. If material is not included in the article's Creative Commons licence and your intended use is not permitted by statutory regulation or exceeds the permitted use, you will need to obtain permission directly from the copyright holder. To view a copy of this licence, visit http://creativecommons.org/licenses/by/4.0/.

\section{References}

Bhattarai M, Pitkänen L, Kitunen V, Korpinen R, Ilvesniemi H, Kilpeläinen PO, Lehtonen M, Mikkonen KS (2019) Functionality of spruce galactoglucomannans in oil-inwater emulsions. Food Hydrocoll 86:154-161

Bhattarai M, Sulaeva I, Pitkänen L, Kontro I, Tenkanen M, Potthast A, Mikkonen KS (2020) Colloidal features of softwood galactoglucomannans-rich extract. Carbohydr Polym 241:116368

Drewnowski A (2001) The science and complexity of bitter taste. Nutr Rev 59:163-169

European Commission (2019) Final circular economy package. http://ec.europa.eu/environment/circular-economy/index_ en.htm. Accessed 13 Apr 2019

Kilpeläinen PO, Hautala SS, Byman OO, Tanner LJ, Korpinen RI, Lillandt MK-J, Pranovich AV, Kitunen VH, Willför SM, Ilvesniemi HS (2014) Pressurized hot water flowthrough extraction system scale up from the laboratory to the pilot scale. Green Chem 12:3186-3194

Konkol Y, Bernoulli J, Streng T, Jääskeläinen K, Laihia J, Leino L (2016) Intravesical treatment with cis-urocanic acid improves bladder function in rat model of acute bladder inflammation. Neurourol Urodyn 35:786-791

Konkol Y, Keskitalo A, Vuorikoski H, Pietilä S, Elo LL, Munukka E, Bernoulli J, Tuomela J (2019) Chronic nonbacterial prostate inflammation in a rat model is associated with changes of gut microbiota that can be modified with a galactoglucomannan-rich hemicellulose extract in the diet. BJU Int 123:899-908

La Rosa SL, Leth ML, Michalak L, Hansen ME, Pudlo NA, Glowacki R, Pereira G, Workman CT, Arntzen M, Pope PB, Martens EC, Hachem MA, Westereng B (2019) The human gut Firmicute Roseburia intestinalis is a primary degrader of dietary $\beta$-mannans. Nat Commun 10:905

Lawless H, Heymann H (2010) Sensory evaluation of food, principles and practices, 2nd edn. Springer, New York

Lahtinen M, Valoppi F, Juntti V, Heikkinen S, Kilpeläinen P, Maina N, Mikkonen KS (2019) Lignin-rich PHWE hemicellulose extracts responsible for extended emulsion stabilization. Front Chem 7:871

Lehtonen M, Teräslahti S, Xu C, Yadav MP, Lampi A-M, Mikkonen KS (2016) Spruce galactoglucomannans inhibit lipid oxidation in rapeseed oil-in-water emulsions. Food Hydrocolloids 58:255-266

Lehtonen M, Merinen M, Kilpeläinen PO, Xu C, Willför SM, Mikkonen KS (2018) Phenolic residues in spruce galactoglucomannans improve stabilization of oil-in-water emulsions. J Colloid Interface Sci 512:536-547

Lestringant P, Delarue J, Heymann H (2019) 2010-2015: how have conventional descriptive analysis methods really been used? A systematic review of publications. Food Qual Prefer 71:1-7

Luke - Natural Resources Institute Finland (2019) Forest industries' wood consumption by branch of industry. http:// statdb.luke.fi/PXWeb/pxweb/en/LUKE/LUKE_04\% 20Metsa_04\%20Talous_08\%20Metsateollisuuden $\%$ 20puunkaytto/02_metsateol_puunk_toimialoittain.px/ table/tableViewLayout2/?rxid=a1c3174c-1532-4f199657-71cb53371ac9. Accessed 26 May 2019

McClements DJ, Bai L, Chung C (2017) Recent advances in the utilization of natural emulsifiers to form and stabilize emulsions. Annu Rev Food Sci Technol 8:205-236

Mikkonen KS (2020) Strategies for structuring diverse emulsion systems by using wood lignocellulose-derived stabilizers. Green Chem 22:1019-1037

Mikkonen KS, Merger D, Kilpeläinen P, Murtomäki L, Schmidt US, Wilhelm M (2016a) Determination of physical emulsion stabilization mechanisms of wood hemicelluloses via rheological and interfacial characterization. Soft Matter 12:8690-8700

Mikkonen KS, Xu C, Berton-Carabin C, Schroën K (2016b) Spruce galactoglucomannans in rapeseed oil-in-water emulsions: efficient stabilization performance and structural partitioning. Food Hydrocoll 52:981-989

Mikkonen KS, Kirjoranta S, Xu C, Hemming J, Pranovich A, Bhattarai M, Peltonen L, Kilpeläinen P, Maina N, Tenkanen M, Lehtonen M, Willför S (2019) Environmentallycompatible alkyd paints stabilized by wood hemicelluloses. Ind Crop Prod 133:212-220

Pitkänen L, Heinonen M, Mikkonen KS (2018) Safety considerations of plant polysaccharides for food use: a case study on phenolic-rich softwood galactoglucomannan extract. Food Funct 9:1931-1943

Ralla T, Salminen H, Edelmann M, Dawid C, Hofmann T, Weiss J (2018) Oat bran extract (Avena sativa L.) from food byproduct streams as new natural emulsifier. Food Hydrocoll 81:253-262 
Rinne M, Kautto O, Kuoppala K, Ahvenjärvi S, Kitunen V, Ilvesniemi H, Willför S, Sormunen-Cristian R (2016) Digestion of wood-based hemicellulose extracts as screened by in vitro gas production method and verified in vivo using sheep. Agric Food Sci 25:13-21

Saadatmand S, Edlund U, Albertsson A-C, Danielsson S, Dahlman O, Karlström K (2013) Turning hardwood dissolving pulp polysaccharide residual material into barrier packaging. Biomacromolecules 14:2929-2936

Sjöström E (1993) Wood Chemistry fundamentals and applications. Academic Press, San Diego

Soares S, Silva MS, García-Estevez I, Großmann P, Brás N, Brandão E, Mateus N, de Freitas V, Behrens M, Meyerhof W (2018) Human bitter taste receptors are activated by different classes of polyphenols. J Agric Food Chem 22:8814-8823

Tuorila H (2015) From sensory evaluation to sensory and consumer research of food: an autobiographical perspective. Food Qual Prefer 40(Part B): 255-262
Valoppi F, Lahtinen M, Bhattarai M, Kirjoranta S, Juntti V, Peltonen L, Kilpeläinen PO, Mikkonen KS (2019a) Centrifugal fractionation of softwood extracts improves biorefinery workflow and yields functional emulsifiers. Green Chem 21:4691-4705

Valoppi F, Maina N, Allén M, Miglioli R, Kilpeläinen PO, Mikkonen KS (2019b) Spruce galactoglucomannan-stabilized emulsions as essential fatty acid delivery systems for functionalized drinkable yogurt and oat-based beverage. Eur Food Res Technol 245:1387-1398

Von Schoultz S (2015) U.S. Patent No. 14,413,409. U.S. Patent and Trademark Office, Washington, DC

Willför S, Rehn P, Sundberg A, Sundberg K, Holmbom B (2003) Recovery of water soluble acetylgalactoglucomannans from mechanical pulp of spruce. Tappi J 2:27-32

Publisher's Note Springer Nature remains neutral with regard to jurisdictional claims in published maps and institutional affiliations. 